\title{
Width of buccal and posterior corridors: Differences between cases treated with asymmetric and symmetric extractions
}

Nuria Cabral Castello Branco', Guilherme Janson², Marcos Roberto de Freitas ${ }^{3}$, Juliana Morais ${ }^{1}$

Objective: To verify if there is difference in the buccal and posterior corridor width in cases treated with extraction of one and four premolars. Methods: Through posed smile photographs of 23 Class II patients, subdivision, treated with extraction of one premolar and 25 Class I and Class II patients, subdivision, treated with extraction of four premolars, the percentage of buccal and posterior corridor width was calculated. The two protocols of extractions were compared regarding the buccal and posterior corridor width by independent t tests. Results: There was no statistically significant difference on the buccal and posterior corridor widths between patients treated with symmetric and asymmetric extraction. Conclusion: The buccal and posterior corridor did not differ between the evaluated protocols of extractions.

Keywords: Orthodontics. Tooth extraction. Premolar.

Objetivo: verificar se há diferença na largura dos corredores bucal e posterior em casos tratados com extrações de um e quatro pré-molares. Métodos: por meio de fotografias do sorriso posado de 23 pacientes Classe II, subdivisão, tratados com extração de um pré-molar, e de 25 pacientes Classe I, Classe II e Classe II, subdivisão, tratados com extração de quatro pré-molares, calculou-se o percentual da largura dos corredores bucais e dos corredores posteriores. Os dois protocolos de extrações foram comparados quanto à largura dos corredores bucal e posterior por meio do teste $t$ independente. Resultados: não houve diferença estatisticamente significativa na largura dos corredores bucal e posterior entre os pacientes tratados com extrações simétricas e assimétricas. Conclusão: o corredor bucal e o corredor posterior não diferiram entre os protocolos de extrações avaliados.

Palavras-chave: Ortodontia. Extração dentária. Pré-molar.

\footnotetext{
» Patients displayed in this article previously approved the use of their facial and intraoral photographs.

${ }^{1} \mathrm{MSc}$ and $\mathrm{PhD}$ Student, FOB-USP.

${ }^{2}$ Head Professor, Department of Pediatric Dentistry, Orthodontics and Public Health, FOB-USP. Chairman, Department of Orthodontics, FOB-USP. Member of Royal College of Dentists of Canada.

${ }^{3}$ Full Professor, Department of Pediatric Dentistry, Orthodontics and Public Health, FOB-USP.
}

How to cite this article: Branco NCC, Janson G, Freitas MR, Morais J. Width of buccal and posterior corridors: Differences between cases treated with asymmetric and symmetric extractions. Dental Press J Orthod. 2012 Sept-Oct;17(5):138-44.

Submitted: April 13, 2009 - Revised and accepted: October 13, 2009.

" The authors report no commercial, proprietary or financial interest in the products or companies described in this article.

Contact address: Nuria Castello Branco

Departamento de Odontopediatria, Ortodontia e Saúde Coletiva

Al. Dr. Octávio Pinheiro Brisola, 9-75 - Zip code: 17012-901 - Bauru/SP - Brazil 


\section{INTRODUCTION}

According to the definition of Frush and Fixher, ${ }^{5}$ buccal corridor is the space between the labial surface of the most posterior tooth and the labial commissure during smile. However, some authors used the distal surface of the canine instead of the labial surface of the posterior tooth as reference. ${ }^{10,18,23}$

For Sarver, ${ }^{24,25}$ one of the factors that leads a patient to have a wide buccal corridor is the maxillary position in relation to the skull base. A patient with retracted maxilla, therefore, could have a wide corridor. Although the maxilla has a normal width, the buccal corridor might seem prominent, for the wider portion of the dental arch is most posterior. However, a study by McNamara ${ }^{18}$ tested this concept and verified that there was no correlation between the buccal corridor and the skull base.

In 1987, it was speculated that the treatment with extractions resulted in constriction of the dental arch, leading to formation of 'negative' lateral spaces. Spahls ${ }^{27}$ said that the removal of a tooth in each quadrant results in a reduction on the radius of curvature of the dental arch. However, Johnson ${ }^{12}$ argued that the dental arch is not a circle that contracts when a tooth is removed. This speculation stimulated some authors to investigate the real consequence of the extractions on the transverse dimension of the arch. ${ }^{6,12,14}$

In order to have a scientific basis about the polemic between extraction of premolars and arch width, Johnson, ${ }^{12}$ through pictures, verified the proportions of the intercanine distance and the distance between the last visible teeth in relation to the smile width of patients treated with and without extraction of four premolars. It was concluded that there was no significant difference on the proportions of the intercanine distance and the distance between the last visible teeth in relation to the smile width, contradicting the speculation that the treatment with extraction of premolars results in a discrepancy between the arch width and the smile width. According to other authors, usually the transverse dimension of the arch is kept or increased after an extraction. What changes is the position that the tooth occupies in the arch. The intermolar distance may decrease after the extraction of premolars, but it is due to the molar movement to a narrower part of the arch. Consequently, the second molar would occupy part of what previously would be the location of the first molar, on the same arch width where this last one was originally found. ${ }^{3,17,20}$

In 2003, Gianelly, ${ }^{6}$ instigated by the speculation of Witzig, ${ }^{27}$ compared through dental casts the intercanine and intermolar distance of patients that were treated with and without extraction of four premolars. It was observed that the arch width, in both groups, was similar, except the intercanine width of the lower arch which was $1 \mathrm{~mm}$ larger after treatment with extractions. Spahl, ${ }^{26}$ after reading Gianelly's article, ${ }^{6}$ wrote a review saying that dental casts cannot give us any information about the human face or the lip support it can or cannot provide.

However, still in 2003, Kim $^{14}$ compared the changes on the widths of anterior and posterior segments of the dental arch of orthodontically treated patients with and without extraction of four premolars. According to the results, there was a reduction of the interpremolar and intermolar distance in both arches on the extraction group, while on the non-extraction group there was an increase. As the anteroposterior position of premolars and molars change during the treatment with extractions, the posterior arch width would be better represented in a specific location, instead of the intermolar and interpremolar distances. This way, by measuring the arch width in a specific arch length on the maxilla and on the mandible, it was observed that the arch width on the extraction group was larger than on the non-extraction one.

The buccal and posterior corridor widths of patients treated with asymmetric and symmetric extractions were not yet compared, which motivated the present study.

\section{MATERIAL AND METHODS}

The sample was constituted of posed smile photographs of 48 patients from the Department of Orthodontics at the School of Dentistry of Bauru-USP, divided in two groups according to protocol of treatment. Group 1 was formed by 23 patients ( 9 men and 14 women) Class II, subdivision, treated with extraction of one premolar. Group 2 was constituted by 25 patients ( 6 men and 19 women), being 3 Class I (1 man and 2 women), 5 Class II (1 man and 4 women) and 17 Class II, subdivision, (4 men and 13 women) patients treated with extraction of four premolars. The mean age of the sample was $23.26 \pm 6.72$ years to group 1 and $25.1 \pm 6.51$ years to group 2 . 
The basic criteria for selection of the sample included the following features: 1) Class II malocclusion, subdivision, treated with extraction of one premolar; 2) class I and II malocclusion and Class II subdivision treated with extraction of four premolars; 3) presence of all permanent teeth until the first molars; 4) absence of tooth size and shape anomalies; 5) absence of active periodontal disease.

As the frontal close-up photograph of the smile is not part of the standard photographic documentation, it was necessary to obtain it from the 48 patients of the sample. To obtain the photos, it was used the following equipment: Photo camera Nikon D40 (Nikon Corporation, Tokyo, Japan); Sigma macro lens $105 \mathrm{~mm}$ and Sigma ring flash (Sigma Corporation of America, New York, USA). All photographs were obtained in manual mode, color, with fine quality, ISO (International Organization for Standardization) 800, minimum aperture at $f 16$ and shutter speed of 60 . The macro lens was adjusted to focus the lips of the patient ${ }^{11}$ at a distance of $60 \mathrm{~cm}$ from the soft tissue, obtaining an image of the lower third of the face, ${ }^{22}$ which goes from the tip of the nose to the middle of the chin. The ring flash was standardized in multi $1 / 4$.

The smile pictures were obtained with the patient sitting down, facing the researcher, so that the lens were at the level of the lips. Each individual was instructed to keep the natural position of the head, which is a standard and reproducible position in an upright and natural posture, with eyes focused in an imaginary spot at the eyes level, resulting in a horizontal vision axis. ${ }^{19}$

The patients were oriented to pose smile ${ }^{8}$ as natural as possible ${ }^{12,14}$ with the teeth in UMI (Usual Maximum Intercuspation). Several photographs were taken of the same patient to choose the best one to be included on the sample. ${ }^{11,12,13}$

Through the Adobe Photoshop 9.0 software (San Jose, CA, USA) it was done the photograph cropping that had as objective to correct the small inclinations of the head and reduce the evaluated area, leaving apparent only part of the skin, the teeth and the $\operatorname{lips}^{2,8,10,12,14,15,21,22,23}$ (Fig 1). For the width and height standardization of the photographs that should be cropped, the widest smile from all the sample was used as size standard, with $21 \mathrm{~cm}$ of intercommissural width, according to the ruler tool from Adobe Photoshop (Fig 2). With the software manipulated to crop the photographs in a proportion of $10 \mathrm{x}$ $17 \mathrm{~cm}$, the height was automatically determined. From that, the measurement to be reproduced on the horizontal and vertical rulers of the software was of $12.2 \times 21 \mathrm{~cm}$. This way, all photographs maintained real size proportions of the dental structures and the soft tissues when seen from the same distance.

Using the Adobe Photoshop 9.0 software, six vertical lines were projected on the images of the smiles and positioned on the outer commissures, distal of upper canines and on the distal of last visible upper
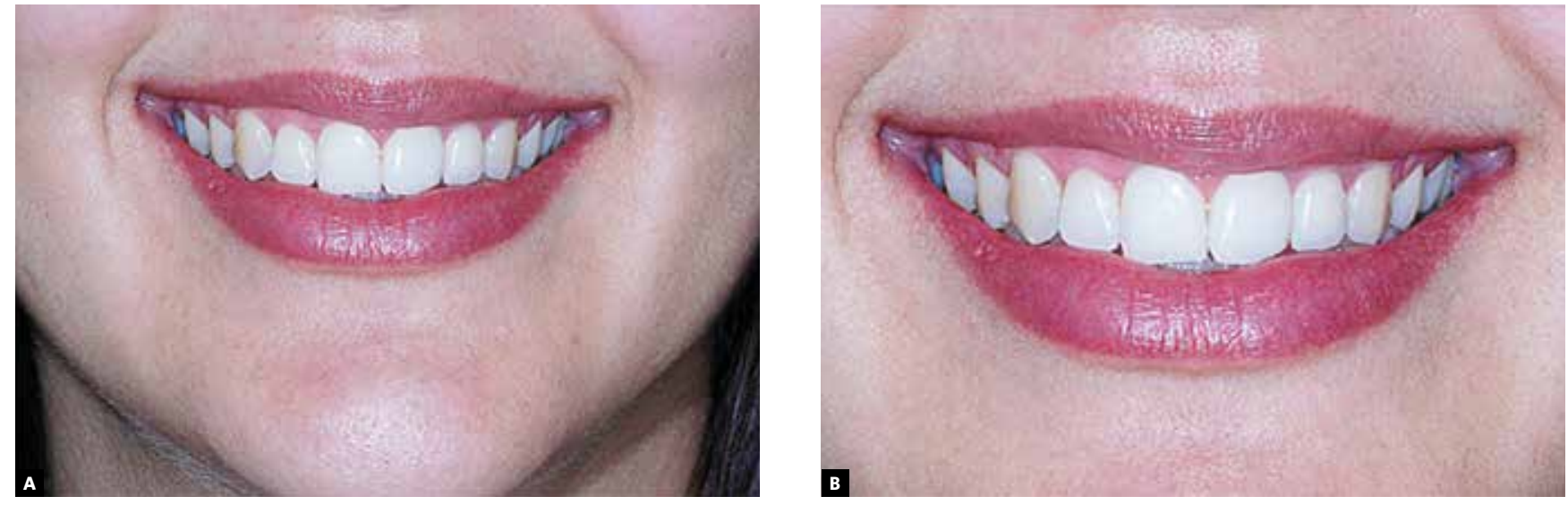

Figure 1 - Photograph cropping. A) Original photograph. B) Photograph after cropping, reducing the area to be evaluated. 

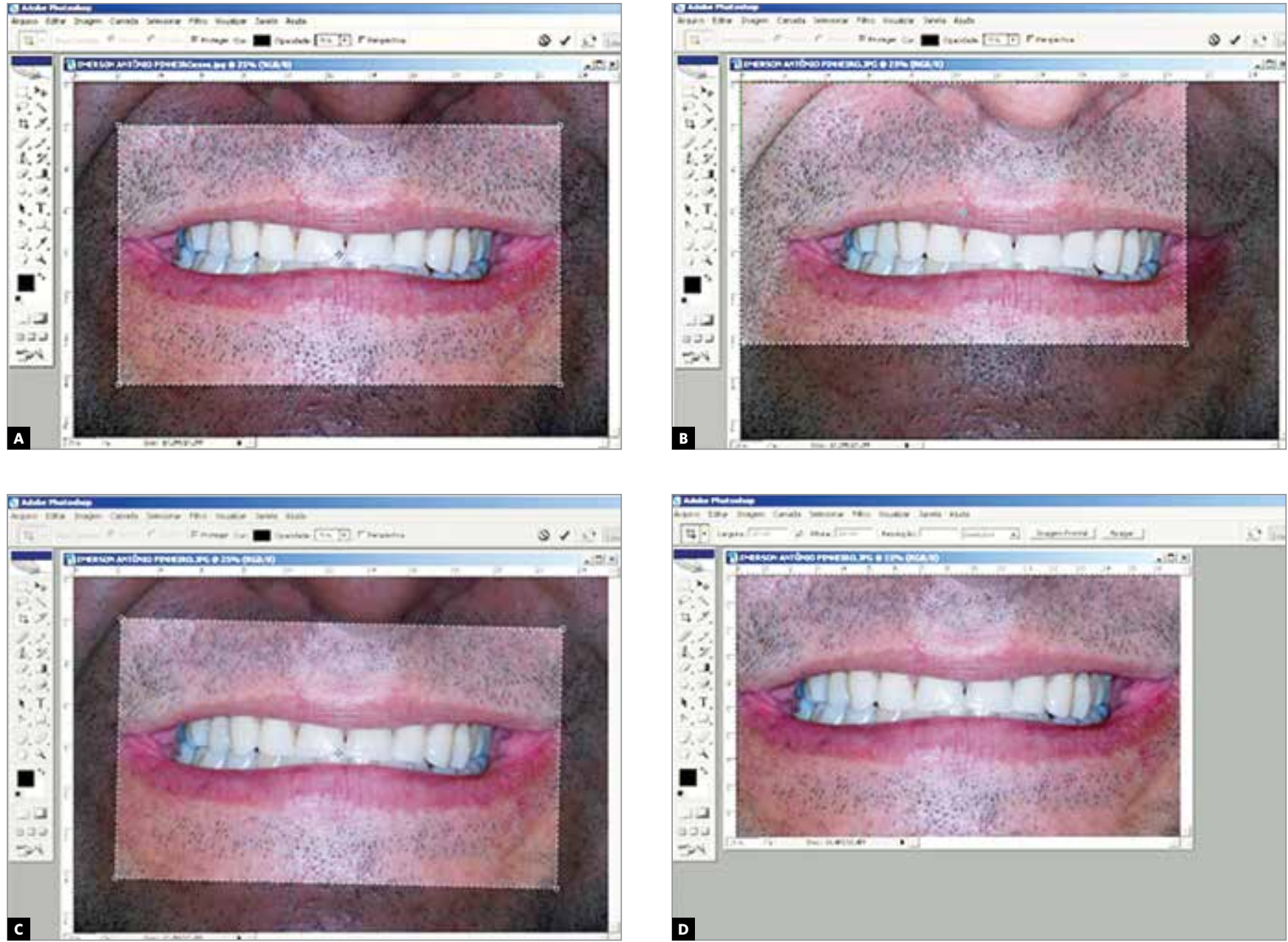

Figure 2 - Standardization of height and width of the photograph by the widest smile from the sample using the Adobe Photoshop 6.0 software. A) Determination of the standard width for photograph cropping by the intercommissural distance using a size proportion defined as $10 \times 17$. B) Verification of height and width measurements to be reproduced on the remaining sample: $12.2 \mathrm{~cm}$ in height and $21 \mathrm{~cm}$ in width. C) Centralization of standard size to be cropped and correction of head inclination. D) Cropped photograph.

posterior teeth (Fig 3). Using this lines as limits, the following smile attributes were measured in millimeters:

» Smile Width (SW): distance between the corners of the lips.

» Upper Intercanine Distance (UID): distance between the most distal point on the right and the most distal point on the left.

» Distance between the Last Visible Teeth of the Maxilla (DLVTM): distance between the most distal point of the last visible posterior tooth on the right and the most distal point of the last visible posterior tooth on the left.

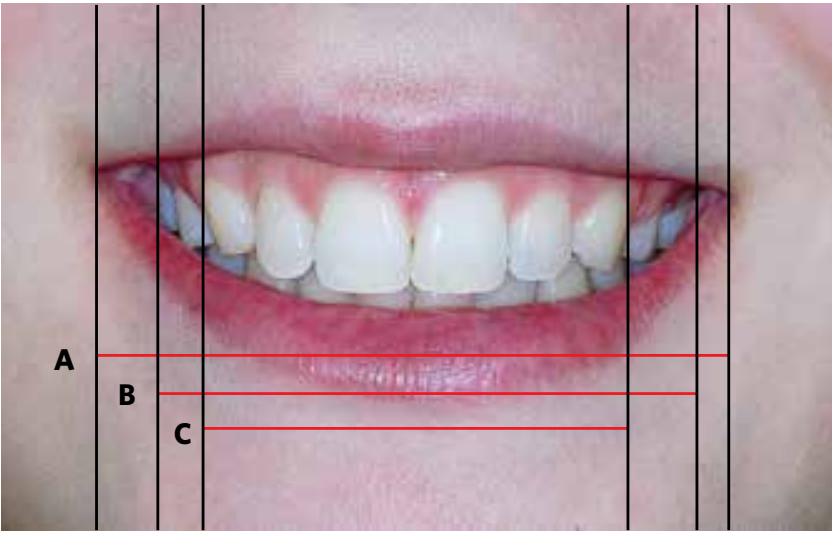

Figure 3 - A) Smile width. B) Distance between the last visible teeth in the maxilla. C) Upper intercanine distance. 
Through these measurements, the proportions in percentage of the buccal and posterior corridor were calculated:

» Buccal corridor: $\frac{\text { SW - UID }}{\text { SW }} 100$ » Posterior corridor: $\frac{\text { SW - DLVTM X } 100}{\text { SW }}$

\section{Statistical analysis}

For evaluation of the researcher's intra-examiner error on the measurement of the buccal and posterior corridors, 12 photographs (6 from each group) were retraced and the smile attributes were measured again with an interval of two weeks after the first measurement. The systematic errors were analyzed by applying the independent $t$ test, according to Houston. ${ }^{9}$ For evaluation of random errors, it was used the Dahlberg error, ${ }^{4}$ which shows the mean variation between the first and the second evaluation/measurement. The test is calculated by the following formula: $\mathrm{Se}^{2}=\Sigma \mathrm{d}^{2} / 2 \mathrm{n}$. The error variation is represented by Se, ${ }^{2} \mathrm{~d}$ is the difference between the first and the second evaluation/measurement and $n$ is the number of double evaluations/measurements. The calculation of the random error was done using a spread sheet from Microsoft Excel XP.

To test the data hypothesis of normality, it was applied the Kolmogorov-Smirnov test for the buccal and posterior corridor measurements in each sample group.

To verify the compatibility regarding the age, the two groups were compared with one another by the independent $t$ test, while the chi-square test determined the genres proportion. Finally, the independent $t$ test was applied to know if there is difference between the size of the buccal corridor and the posterior corridor between the two groups. All tests were performed with Statistica program (Version 6.0; StatSoft Inc., Tulsa, OK, USA), using a significance level of $5 \%$.

Table 1 - Results of the paired t test and the Dahlberg's formula applied to measurement of the variables smile width (SW), upper intercanine distance (UID) and distance between the last visible teeth of the maxilla (DLVTM) to evaluate the systematic and random intra-examiner errors, respectively.

\begin{tabular}{|c|c|c|c|c|c|c|}
\hline \multirow{2}{*}{ Smile attributes } & \multicolumn{2}{|c|}{ 1st measurement $(n=14)$} & \multicolumn{2}{|c|}{ 2nd measurement $(n=14)$} & \multirow[b]{2}{*}{$\mathbf{p}$} & \multirow{2}{*}{ Dahlberg } \\
\hline & Mean & SD & Mean & SD & & \\
\hline SW & 13.15 & 1.03 & 13.15 & 1.21 & 1 & 0.18 \\
\hline UID & 8.12 & 0.35 & 8.21 & 0.39 & 0.23 & 0.18 \\
\hline DLVTM & 10.71 & 0.59 & 10.66 & 0.69 & 0.46 & 0.19 \\
\hline
\end{tabular}

Table 2 - Results of the intergroup comparisons (independent $t$ test and chi-square).

\begin{tabular}{cccc} 
Variables & Group 1 $(\mathbf{n}=\mathbf{2 3})$ & Group 2 (n= 25) \\
Age & $23.26 \pm 6.72$ & $25.10 \pm 6.51$ \\
Gender & & & $0.3400^{*}$ \\
Masculine & 9 & 6 & $0.2586^{* *}$ \\
\hline Feminine & 14 & 19 \\
\hline
\end{tabular}

*Independent $t$ test; ${ }^{\star \star}$ chi-square.

Table 3 - Results of the independent $t$ test to compare the percentage of the BC (buccal corridor) width and PC (posterior corridor) width between group 1 (treatment with extraction of one premolar) and group 2 (treatment with extraction of four premolars).

\begin{tabular}{cccccc}
\multirow{2}{*}{ Variables } & \multicolumn{2}{c}{ Group 1 $(\mathbf{n = 2 3 )}$} & & Group 2(n=25) \\
\cline { 2 - 5 } & Mean & SD & Mean & SD \\
\hline Buccal corridor & 39.46 & 4.01 & 37.56 & 4.72 \\
Posterior corridor & 17.76 & 5.29 & 18.53 & 5.60 \\
\hline
\end{tabular}




\section{RESULTS}

Table 1 shows results of the paired $t$ test and Dahlberg's formula applied to measurement of the variables smile width (SW), upper intercanine distance (UID) and distance between the last visible teeth of the maxilla (DLVTM) to evaluate the systematic and random intra-examiner errors, respectively.

On Table 2, the results of independent $t$ test applied on evaluation of compatibility of the groups 1 and 2 regarding the age are demonstrated. It also displays results of the chi-square test regarding the genres proportion.

Table 3 presents results of independent $t$ test, applied to compare the size of buccal and posterior corridor between the groups.

\section{DISCUSSION}

\section{Method accuracy and \\ Sample compatibility}

The significant absence of systematic errors and the reduced value of detected random errors, in this study, result from the evaluation and accuracy of measurements of the smile attributes by the researcher (Table 1).

The mean age for both groups were statistically similar. Regarding the distribution of genres, the groups were statistically similar although the sample presented, numerically, more female individuals than male individuals (Table 2).

\section{Comparison result of buccal and posterior corridor between patients treated with symmetric and asymmetric extractions}

One of the criticisms for premolars extraction concerns to the relation between the arch width and the smile width. ${ }^{12}$ Spahl ${ }^{27}$ argued that the removal of a tooth in each quadrant results in reduction on radius of curvature of the dental arch, contracting the arch and leading to a dentition that is not enough to fill in the buccal cavity during smile. In a study performed by Johnson, ${ }^{12}$ there was no difference on the proportion of intercanine width and the distance between the last visible posterior teeth of the smile in patients orthodontically treated with and without extraction of four premolars, contradicting that treatments with extractions result in a discrepancy between the arch width and the soft tissues. Kim, ${ }^{14}$ by measuring the upper and lower arch width, in a constant arch depth, of cases treated with and without extraction of four premolars verified that, actually, on the extraction group the arches were from 1 to 2 mm wider when compared to patients without extractions. In this study, analyzing the buccal and posterior corridor width, in cases treated with extraction of one and four premolars, it was observed that there was also no statistically significant difference between the two groups (Table 3 ). It is incorrect to believe that extraction of premolars results in a reduction on radius of curvature of the dental arch, for the arch is not a circle and does not behave as a circle. ${ }^{12}$ If the treatment with extractions leads to a contraction of dental arches, then the buccal corridor width in individuals with extraction of one premolar should be smaller than the extraction group of four premolars.

In this study, the proportions of the buccal corridor found were of $39.46 \%$ and $37.56 \%$, while the proportions of the posterior corridor were of $17.76 \%$ and $18.53 \%$ for the groups with extraction of one and four premolars, respectively (Table 3). Ritter $^{22}$ found a mean value of $19.20 \%$ for the posterior corridor in patients with good dental alignment not orthodontically treated. In a later study, McNamara ${ }^{18}$ observed an equivalent proportion of $36.6 \%$ for the buccal corridor and $24.71 \%$ for the posterior corridor in patients that sought orthodontic treatment.

One factor that might have affected the results, causing this size difference on buccal and posterior corridors between the studies, is the illumination condition in which the photographs were taken. As the teeth are positioned more posteriorly on buccal corridors, the light is reduced, which causes a gradual darkening and, consequently, a poor observation of the posterior teeth. ${ }^{5,7,16,23}$ The less illumination on the photograph, the larger is the buccal corridor, for less teeth are observed, reducing the arch width when the smile width is the same. ${ }^{22}$ This way, what would be called "negative space"16 is not really a space, but only an illusion. ${ }^{1}$ This possible difference on the standardization of illumination conditions between studies is a factor that complicates the comparison between them. ${ }^{22}$

\section{Clinical considerations}

There was a dogma that the treatment with extraction resulted in contraction of the dental arch 
and led to an increase of the buccal corridor. ${ }^{27}$ However, several studies showed that there is no difference on the buccal corridor width between cases treated with and without extraction of four premolars and a control group..$^{11,12,14}$ This work demonstrated that among individuals treated with extractions of one and four premolars there is also no difference on the buccal and posterior corridors width, excluding a possible criticism to the protocol of asymmetric extractions in the Class II malocclusion, subdivision.

\section{CONCLUSION}

Buccal and posterior corridor width were not affected by the protocols of extractions of one and four premolars.

\section{REFERENCES}

1. Ackerman MB, Ackerman JL. Smile analysis and design in the digital era. J Clin Orthod. 2002 Apr;36(4):221-36.

2. Andrade F, Souza D, Nascimento AP, Gomes A. Percepção estética entre as especialidades odontológicas. UFES Rev Odontol. 2006;8(1):46-54.

3. Bishara SE, Cummins DM, Zaher AR. Treatment and posttreatment changes in patients with Class II, Division 1 malocclusion after extraction and nonextraction treatment. Am J Orthod Dentofacial Orthop. 1997 Jan;111(1):18-27.

4. Dahlberg G. Statistical methods for medical and biological students. London (UK): G. Allen \& Uniwin; 1940

5. Frush JO, Fisher RD. The dynesthetic interpretation of the dentogenic concept. J Prosthet Dent. 1958;8(4):558-2.

6. Gianelly AA. Arch width after extraction and nonextraction treatment. Am J Orthod Dentofacial Orthop. 2003 Jan;123(1):25-8.

7. Graber LW, Lucker GW. Dental esthetic self-evaluation and satisfaction. Am J Orthod. 1980 Feb;77(2):163-73.

8. Gracco A, Cozzani M, D'Elia L, Manfrini M, Peverada C, Siciliani G. The smile buccal corridors: aesthetic value for dentists and laypersons. Prog Orthod. 2006;7(1):56-65.

9. Houston WJ. The analysis of errors in orthodontics measurements. Am J Orthod. 1983 May;83(5):382-90.

10. Hulsey CM. An esthetic evaluation of lip-teeth relationships present in the smile. Am J Orthod. 1970 Feb;57(2):132-44.

11. I iksal E, Hazar S, Akyalçin S. Smile esthetics: perception and comparison of treated and untreated smiles. Am J Orthod Dentofacial Orthop. 2006 Jan;129(1):8-16.

12. Johnson DK, Smith RJ. Smile esthetics after orthodontic treatment with and without extraction of four first premolars. Am J Orthod Dentofacial Orthop. 1995 Aug;108(2):162-7.

13. Kerns LL, Silveira AM, Kerns DG, Regennitter FJ. Esthetic preference of the frontal and profile views of the same smile. J Esthet Dent. 1997;9(2):76-85.

14. Kim E, Gianelly AA. Extraction vs nonextraction: arch widths and smile esthetics. Angle Orthod. 2003 Aug;73(4):354-8.

15. Kokich VO, Kokich VG, Kiyak HA. Perceptions of dental professionals and laypersons to altered dental esthetics: asymmetric and symmetric situations. Am J Orthod Dentofacial Orthop. 2006 Aug;130(2):141-51.
16. Lombardi RE. The principles of visual perception and their clinical application to denture esthetics. J Prosthet Dent. 1973 Apr;29(4):358-82.

17. Luppanapornlarp S, Johnston LE Jr. The effects of premolar-extraction: a long-term comparison of outcomes in "clear-cut" extraction and nonextraction Class II patients. Angle Orthod. 1993 Winter;63(4):257-72.

18. McNamara L, McNamara JA Jr, Ackerman MB, Baccetti T. Hard- and soft-tissue contributions to the esthetics of the posed smile in growing patients seeking orthodontic treatment. Am J Orthod Dentofacial Orthop. 2008 Apr;133(4):491-9.

19. Moorrees CF. Natural head position--a revival. Am J Orthod Dentofacial Orthop. 1994 May;105(5):512-3.

20. Paquette $D E$, Beattie JR, Johnston LE Jr. A long-term comparison of nonextraction and premolar extraction edgewise therapy in "borderline" Class II patients. Am J Orthod Dentofacial Orthop. 1992 Jul;102(1):1-14.

21. Pinho S, Ciriaco C, Faber J, Lenza MA. Impact of dental asymmetries on the perception of smile esthetics. Am J Orthod Dentofacial Orthop. 2007 Dec;132(6):748-53.

22. Ritter DE, Gandini LG, Pinto Ados S, Locks A. Esthetic influence of negative space in the buccal corridor during smiling. Angle Orthod. 2006a Mar;76(2):198-203..

23. Roden-Johnson D, Gallerano R, English J. The effects of buccal corridor spaces and arch form on smile esthetics. Am J Orthod Dentofacial Orthop. 2005 Mar;127(3):343-50.

24. Sarver DM. The importance of incisor positioning in the esthetic smile: the smile arc. Am J Orthod Dentofacial Orthop. 2001b Aug:120(2):98-111.

25. Sarver DM, Ackerman MB. Dynamic smile visualization and quantification: part 1. Evolution of the concept and dynamic records for smile capture. Am J Orthod Dentofacial Orthop. 2003a Jul;124(1):4-12..

26. Spahl TJ. Premolar extractions and smile esthetics. Am J Orthod Dentofacial Orthop. 2003 Jul;124(1):16A-17A; author reply 17A.

27. Spahl TJ, Witzig JW. The clinical management of basic maxillofacial orthopedic appliances. Litteton (MA): PSG Cop; 1987. 